\title{
Correction to: Management of immune thrombocytopenia in multiple sclerosis patients treated with alemtuzumab: a Belgian consensus
}

\author{
Catherine Lambert ${ }^{1}$ (D) Benedicte Dubois ${ }^{2} \cdot$ Dominique Dive $^{3} \cdot$ Andreas Lysandropoulos $^{4} \cdot$ Dominik Selleslag $^{5}$. \\ Ludo Vanopdenbosch ${ }^{6}$. Vincent Van Pesch ${ }^{7}$. Bart Vanwijmeersch ${ }^{8}$. Ann Janssens ${ }^{9}$
}

Published online: 3 March 2018

(c) Belgian Neurological Society 2018

\section{Correction to: Acta Neurologica Belgica https://doi.org/10.1007/s13760-018-0882-3}

The article Management of immune thrombocytopenia in multiple sclerosis patients treated with alemtuzumab: a Belgian consensus, written by Lambert et al., was originally published electronically on the publisher's internet portal on 27 January 2018 without open access.

With the author(s)' decision to opt for Open Choice the copyright of the article changed on March 3, 2018 to (C) The Author(s) 2018 and the article is forthwith distributed under the terms of the Creative Commons Attribution 4.0 International License (http://creativecommons.org/licenses/ by/4.0/), which permits use, duplication, adaptation, distribution and reproduction in any medium or format, as long as you give appropriate credit to the original author(s) and the source, provide a link to the Creative Commons license and indicate if changes were made.

The original article has been corrected.

The original article can be found online at https://doi.org/10.1007/ s13760-018-0882-3.

Catherine Lambert

catherine.lambert@uclouvain.be

1 Department of Hematology, Cliniques Universitaires St Luc, Brussels, Belgium

2 Department of Neurology, Universitaire Zienkenhuis Leuven, Leuven, Belgium

3 Departement of Neurology, CHU Liège, Esneux, Belgium

4 Neuroimmunology - MS Unit, Neurology Department, CUB- Hôpital Erasme, Brussels, Belgium

5 Department of Hematology, AZ Sint-Jan, Brugge, Belgium

6 Department of Neurology, AZ Sint Jan, Brugge, Belgium

7 Department of Neurology, Cliniques Universitaires St Luc, Brussels, Belgium

8 Departement of Neurology, Rehabilitation and MS Center, Overpelt, Belgium

9 Department of Hematology, Universitaire Ziekenhuizen Leuven, Leuven, Belgium 